\title{
Traumatic Brain Injury During the Prodromal Phase of Parkinson's Disease
}

\author{
Parkinson Hastalığının Prodromal Döneminde Travmatik Beyin Hasarı
}

Keywords: Traumatic brain injury, Parkinson's disease, prodromal phase, association

Anahtar Kelimeler: Travmatik beyin hasarı, Parkinson hastalı̆̆ı, prodromal dönem, ilişki

\section{Traumatic Brain Injury During Prodromal Period of Parkinson's Disease}

Falls are the leading cause of traumatic brain injury (TBI) (1). It is known that elderly people with Parkinson's disease (PD) are at a greater risk of falls than the general elderly population. In a study on early-stage PD, $48 \%$ of patients reported having experienced at least one fall within a 6-month period (2). On the other hand, it is suggested that the patients with PD in the prodromal period may also have an increased risk of falls. Considering that the falls may result in TBI, it has recently been debated whether the relationship between PH and TBI is causal (3).

In light of this information, in an important recently published study, Camacho-Soto et al. (3) sought answers to questions such as whether the risk of TBI increased as patients approached the diagnosis of PD in their prodromal period (3). Individuals aged 66 to 90 years, had health insurance claim data between 2004 and 2009 and living in the United States in 2009 were included in the study. During this 5-year period, "PD patients in the prodromal period" group was formed from individuals who had been followed up and diagnosed as having PD. Patients with possible atypical parkinsonism and Lewy body dementia were excluded from the study. Controls were randomly selected from all remaining health insurance beneficiaries. Randomization was not performed in terms of demographic factors, and the effect of these factors was analyzed in risk factor analyzes. TBI up until the PD diagnosis was the primary outcome of interest. TBI was identified using the Centers for Disease Control and Prevention (CDC) criteria and classified as mild versus moderate/severe. Trauma mechanism was divided into the following categories: falls, motor vehicle accidents, and other mechanisms. In addition, the authors also evaluated 14 separate codes recorded in the system during followup, which may be potentially confusing or indirectly related when examining the entire association between TBI and PD. Four of these codes included possible motor dysfunction (abnormal gait, loss of coordination, fall), and the other 10 were identified as those associated with dementia/cognitive impairment.

A total of 89,790 patients with PD and 118,096 controls were included in the study. Nineteen percent of patients with $\mathrm{PD}$ and $7 \%$ of controls were found to have a TBI diagnosis in the 5-year follow-up. It was determined that $84 \%$ (both in the PD and control group) of all TBIs were mild. Among individuals with certain causes of trauma, it was determined that TBI was associated with a fall in $82 \%$ of patients with PD and $74 \%$ of controls. According to hazard rate function, patients with PD in their prodromal period were more likely to have a TBI compared with controls in the comparable period. The Cox regression model, which adjusted for age, sex, and race/ethnicity, confirmed that a significant difference was observed in all time periods (pre-PD; 5-4, 4-3, 3-2, 2-1, 1-0 years). It was determined that the incidence of TBI was consistently increasing as the PD diagnosis approached and that the highest rates were in the year immediately preceding the PD diagnosis.

In the results of the study, gait disturbance, loss of coordination, and past history of falls were identified as important sub-factors that were effective in the PH-TBI relationship. At the same time,

\footnotetext{
Address for Correspondence/Yazışma Adresi: Halil Önder MD, Yozgat City Hospital, Clinic of Neurology, Yozgat, Turkey Phone: +90 5376836864 E-mail: halilnder@yahoo.com ORCID ID: orcid.org/0000-0002-1823-2278

Received/Geliş Tarihi: 13.11.2017 Accepted/Kabul Tarihi: 06.12.2017

${ }^{\odot}$ Copyright 2018 by Turkish Neurological Society

Turkish Journal of Neurology published by Galenos Publishing House.
} 
cognitive and psychiatric diseases have also been found to be important in this respect. In this context, the study results suggest that a combination of non-motor and motor symptoms preceding PD diagnosis may contribute to TBIs through falls.

Some of the limitations of the study can also be mentioned. First, the authors were unable to consider TBIs that occurred more than 5 years before PD diagnosis. Given the views that TBI may be a causal factor in the development of PD, this study design could not exclude the possibility that TBIs in earlier life might have contributed to the development of PD. Second, there may have been some problems with the classification of TBI and the diagnosis of PD due to the retrospective nature of the study.

The most important implication of this study was the finding of the marked increase in incidence of TBI preceding clinical PD diagnosis and the authors emphasized the possible importance of earlier diagnosis of PD for primary prevention of TBI. The results of this report provide very important information on the relationship between TBI and PD because a very large group of individuals was included. However, it can be predicted that the results of future prospective studies with longer follow-up periods may provide important contributions to the incidence of TBI in patients with PD and the possible role of TBI in the development of PD.

\section{References}

1. Taylor CA, Bell JM, Breiding MJ, Xu L. Traumatic Brain Injury-Related Emergency Department Visits, Hospitalizations, and Deaths - United States, 2007 and 2013. MMWR Surveill Summ 2017;66:1-16.

2. Kerr GK, Worringham CJ, Cole MH, Lacherez PF, Wood JM, Silburn PA. Predictors of future falls in Parkinson disease. Neurology 2010;75:116-124.

3. Camacho-Soto A, Warden MN, Searles Nielsen S, Salter A, Brody DL, Prather H, Racette BA. Traumatic brain injury in the prodromal period of Parkinson's disease: A large epidemiological study using medicare data. Ann Neurol 2017;82:744-754. 